\title{
Experimental Characterization of Aircraft Electromagnetic Protections
}

\author{
David KRUTILEK, Zbynek RAIDA, Jiri DRINOVSKY \\ Dept. of Radio Electronics, Brno University of Technology, Technická 12, 61600 Brno, Czechia \\ $\{106568$, raida,drino\}@vut.cz
}

Submitted August 10, 2021 / Accepted October 14, 2021

\begin{abstract}
In the paper, an original construction of a coaxial flange for measurements of shielding efficiency of composite materials is presented. The measurement procedure is conceived as a differential method to suppress influence of a flange. Attention is turned to measurements of carbon composites used in aerospace industry. The studied materials exhibit a significant ability to shield electromagnetic radiation. The shielding efficiency is rising with material thickness and with the number of fiberto-fiber contacts. The optimal composite structure consists of 4 layers of carbon composite; more layers do not influence the shielding efficiency significantly.
\end{abstract}

\section{Keywords}

Carbon composite, carbon-fiber-reinforced polymer (CFRP), glass-fiber composite (GFC), shielding efficiency, measurements, aerospace applications, coaxial flange

\section{Introduction}

Historically, magnesium-based alloys, plastic and fabric materials or wood were exploited for aircraft construction. Since mid-1950s, conventional materials have been replaced by non-conventional ones like reinforced plastics and advanced composites. Even the use of aluminum and aluminum alloys has been notably diminishing from $80 \%$ to only around $15 \%$ of airframes [1].

In order to enhance aircraft design, the aircraft industry began to produce synthetic fibers, and the use of composite materials has been increasing. Speaking about composites, the fiberglass, the graphite or aramids (Kevlar) have been usually considered [2]. Pioneered by aviation and aircraft industry, other industries have included composites into their production as well. Auto racing, sport equipment, boating and defense industry belong to typical examples.

The composite can be defined as a structure being composed from different materials. Such a general definition may refer to metal alloys which are made from various metals to enhance diverse characteristics, such as strength, ductility, conductivity or other desired properties.

Similarly, the composition of composite materials can be seen as a combination of reinforcement components, e.g. a fiber, a whisker, or a particle [3]. These components form a structure being surrounded and held in place by a resin. When separated, reinforcement and resin are of totally different properties than when combined. Even in their combined state, a possibility of identification and mechanical separation of components stay preserved.

As an example, a concrete can be given. The concrete is a composite being composed of cement (resin) and gravel or reinforcement rods to reinforce the material.

Compared to traditional materials used in aircraft industry, composites excel in an increased strength, and an ability to accommodate the performance needs. Moreover, the costs, the design and inspection ease, as well as the strength to weight criterion help composites to become the material of choice for aircraft construction [4].

On the other hand, electrical conductivity and shielding efficiency of composites is lower compared to fully metallic structures. Therefore, the shielding efficiency has to be measured to ensure the requested electromagnetic properties of the composite structure [5], [6].

In [7], authors discussed theoretical and practical aspects of measurement of shielding efficiency by a coaxial flange. Here, the concrete with carbon fibers was the measured composite material. Using a vector network analyzer, frequency response of scattering parameters was recorded in the frequency range from $9 \mathrm{kHz}$ to $1 \mathrm{GHz}$, and shielding efficiency was evaluated afterwards. Outputs of measurements by the coaxial flange were verified by antenna measurements and reference measurements using brass in the flange.

In IEEE Xplore, approximately 100 papers focused on measurements of shielding efficiency of composite materials have been published in last 5 years. A significant number of papers is focused on measurements of:

- Textile-based composite materials; e.g. [9], [10];

- Graphite-based materials; e.g. [11];

- Magnetic materials; e.g. [12], [13] 
- $\quad$ Epoxy materials; e.g. [14];

- Cement-based materials; e.g. [15], [16].

From the viewpoint of this paper, measurements of CFRP materials are relevant. In [17], free-space measurements were applied using a mono-conic antenna. Measurement outputs were analyzed considering needs of automotive applications.

Next to the automotive applications, attention has been also turned to the protection of computer systems [18] and biomedical applications [19]. Pure aircraft applications have been discussed in [20] to [22].

In [7], [8], [20-22], the ASTM D4935 standard was followed using a conventional coaxial flange. A deeper consideration of specific properties of aircraft composites resulted in the design of an original coaxial flange. In the paper, the new flange is compared with [7] in detail to show differences.

In Sec. 2, the designed coaxial flange is described and compared with the existing one presented in [8]. Measurement uncertainties are discussed in Sec. 3. In Sec. 4, samples of aircraft composites are measured and their optimal structure is discussed. Section 5 concludes the paper.

Measurements have been verified by numerical simulations in CST Studio Suite. The comparison approves validity of results.

Measurement of shielding efficiency is very important in the area of radio engineering. Thanks to the proper shielding, low-power signals (e.g., an on-board communication in the airplane) can be protected against high-power interferences (e.g., high intensity radiated fields generated outside the airplane).

Specific composite materials used for the construction of airplanes require specific modifications of conventional measurement techniques. For this reason, the presented differential method was developed and the originally modified flange was designed.

\section{Coaxial Flange and Samples}

The coaxial flange is suitable for measuring the farfield electromagnetic (EM) shielding efficiency (SE) of planar materials. From the measured data, near-field SE values may be calculated for magnetic $(H)$ sources and electrically thin samples [9-25]. Electric (E) field SE values may be calculated from identical far-field data, but their validity and applicability have not been established.

The measurement method is valid over a frequency range from $30 \mathrm{MHz}$ to $1.5 \mathrm{GHz}$. The frequency limits are based on decreasing displacement currents caused by the decreased capacitive coupling at lower frequencies and an over-moding [25] at higher frequencies. The overmoding denotes an excitation of modes other than the transverse electromagnetic one (TEM).
A number of discrete frequencies should be selected within the range of measurement. For electrically thin, isotropic materials with frequency independent electrical properties (conductivity, permittivity, permeability), the measurement at few frequencies is sufficient since the farfield SE values are frequency-invariant. If the material is not electrically thin or the parameters vary with frequency, measurements should be performed at more frequencies within the band of interest.

\subsection{Coaxial Flange}

A fundamental equipment setup is shown in Fig. 1. The coaxial flange is connected to the network analyzer. Physical dimensions of a coaxial flange are given in D4935-10 [26].

Figure 2 shows a half of a flange spread into particular structural elements. The coaxial flange is enlarged. The coaxial transmission line with special taper sections is completed by notched matching grooves to keep the characteristic impedance $50 \Omega$ throughout the entire length of the flange [27]. The impedance is checked and values higher than $60.5 \Omega$ are corrected. flange:

Three aspects are important when designing the

- The pair of flanges holds the sample. This allows the capacitive delivery of energy into insulating materials through displacement currents.

- A reference sample of the same thickness and electrical properties as the load sample causes the same discontinuity in the transmission line as caused by the load sample.

- Nonconductive (nylon) screws are used to connect two sections of the holder together during tests. This prevents the conduction of currents so that the desired displacement currents can dominate. This behavior is necessary for the correct operation of the sample holder.

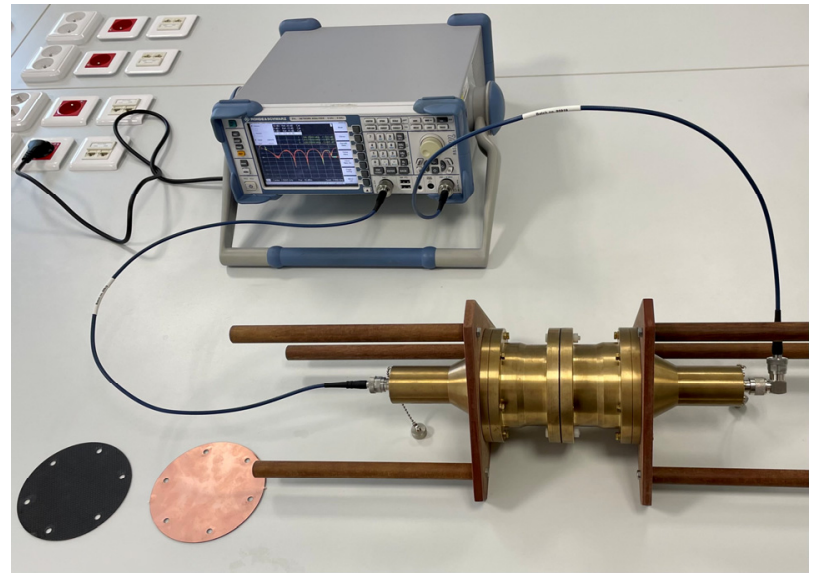

Fig. 1. Measurement of shielding efficiency: the fundamental measurement setup. 


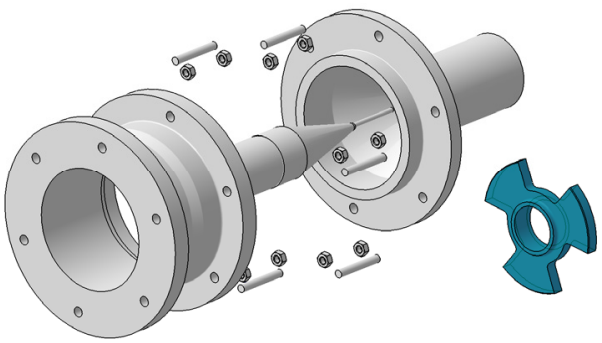

Fig. 2. Half of coaxial flange. Grey: parts from brass. Blue: parts from plexiglass.

Comparing the designed coaxial flange with [7], the following differences can be identified:

- Since a set of two samples is measured (a reference one and a load one), the influence of the coaxial flange to the measurement results is compensated.

- Thanks to the flange construction, there are no practical restrictions on the measured sample size.

- A wider frequency range of measurements is reached (1.5 GHz versus 1.0 GHz in [7]).

Thanks to the described modifications of the flange, the shielding efficiency can be measured more accurately compared to [7].

Measurements [26] are no longer supported and further developed by ASTM. Nevertheless, [6] is still frequently used due to the simplicity and the ease of use.

Measurements [26] do not require large transmitting and receiving antennas, shielded TEM cells or shockless chambers. Only a relatively small sample of a shielding material is needed to determine the shielding efficiency. Thus, measurements [26] are particularly suitable for research laboratories and development facilities that develop and test novel shielding materials (thin conductive films, shielding fabrics, etc.).

\subsection{Test Samples}

For measurements, a set of two samples is used: a reference sample and a load one. The load sample and the reference one should be of the same thickness and should consist of the same material. As depicted in Fig. 3, both the samples are stored in the coaxial flange.

Dimensions of samples are given in [26]. The annulus of the reference sample has diameters $r_{\text {in }}=33.0 \mathrm{~mm}$ and $r_{\text {out }}=76.2 \mathrm{~mm}$. The load sample can be larger than the outer diameter of the flange on the holder but keeping them to the recommended dimensions will speed up handling.

Thickness of samples is a critical dimension. For the best repeatability of measurements, thickness of the reference sample and the load sample should be identical and should meet the condition [26]:

$$
t \leq \lambda / 100 \text {. }
$$

Here, $\lambda$ is the wavelength of electromagnetic wave propagating at the frequency of measurement within the sample.

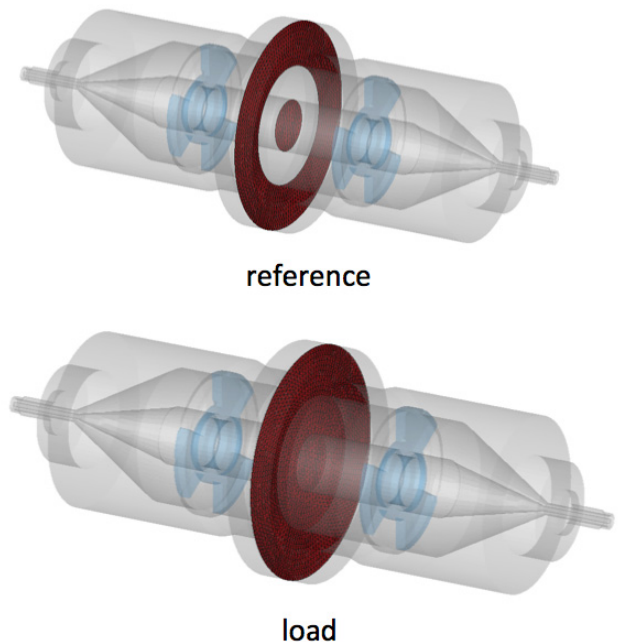

Fig. 3. Samples in coaxial flange. Top: the reference sample. Bottom: the load sample.

Thickness $t$ of samples is considered to be identical if the difference $\Delta t_{\mathrm{a}}<25 \mu \mathrm{m}$ and the $\Delta t_{\mathrm{a}} / t_{\mathrm{a}}<5 \%$ where the subscript a denotes the average value.

Materials of samples can be both homogeneous and inhomogeneous, both single-layered and multi-layered, both conductive and non-conductive. The measured shielding efficiency of inhomogeneous materials depends on geometry and orientation of the sample, and repeatability is worse than in case of homogeneous materials.

\subsection{Measurement Procedure}

Measured samples are clamped between the mirrored halves of the holder (see Fig. 3). Shielding efficiency is computed as a ratio of the incident power and the power transmitted by the load sample.

After the calibration of the network analyzer, the coaxial flange is connected and the dynamic range is determined. The dynamic range can be checked by comparing the maximum signal level (no sample in the flange) and the

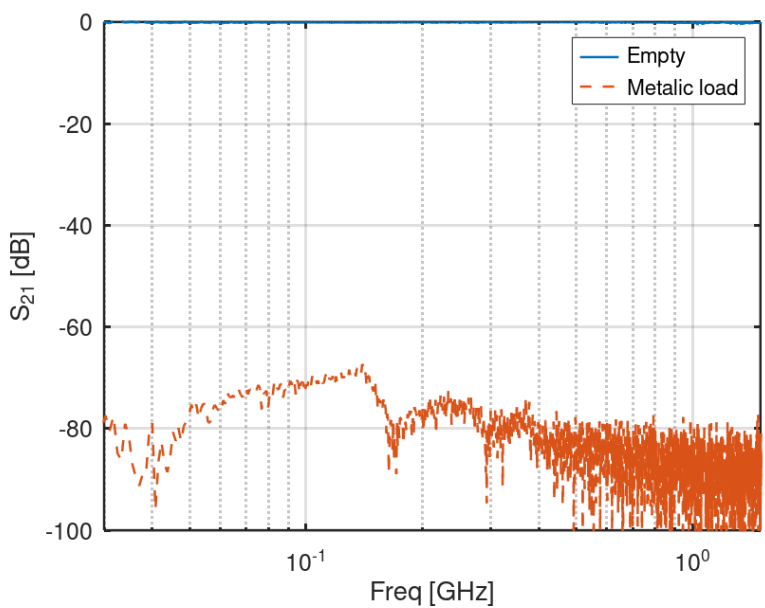

Fig. 4. Determination of the dynamic range: frequency responses of transmission coefficient for empty flange (blue) and flange with metallic load (red). 
minimum one (metallic load sample). In Fig. 4, frequency responses of transmission coefficient for both the cases are depicted.

The lower limit of the measurement system sensitivity is evaluated as a function of the sensitivity and the bandwidth of the receiver. Narrowing the bandwidth of the receiver lowers the detectable signal level but increases the measurement time.

Leakage caused by connectors or cables may reduce the dynamic range of the system because a parallel signal path, which does not pass through the sample, is created. If a step attenuator is connected in series with the holder, the detected minimum signal level is changed according to the attenuator setting. If the step attenuator does not create a leakage path, the leakage is negligible and the dynamic range is measured correctly. If signal levels do not correspond, the attenuation should be increased until a one-toone correspondence is achieved.

Since the leakage from a coaxial connector is given not only by the quality of the connector, but also by the torque when tightening the connector, connections should be rechecked.

\subsection{Holder Verification}

The sample holder should be initially checked by a time-domain reflectometer or another suitable instrument to ensure that the characteristic impedance $50.0 \pm 0.5 \Omega$ can be guaranteed. A time-domain system provides both the magnitude and the location of a mismatch. Each time the auxiliary equipment is connected to the sample holder, a reference sample has to be measured.

Scattering parameters of the manufactured coaxial flange without a sample were verified by comparing simulated and measured frequency responses. In Fig. 5, measured responses are compared with transient simulations in CST Microwave Studio. Since the flange is symmetrical, only the $S_{11}$ and $S_{21}$ are compared for clarity. The S-parameter $S_{11}$ is identical with $S_{22}$ and $S_{12}$ with $S_{21}$, as discussed later in the paper.

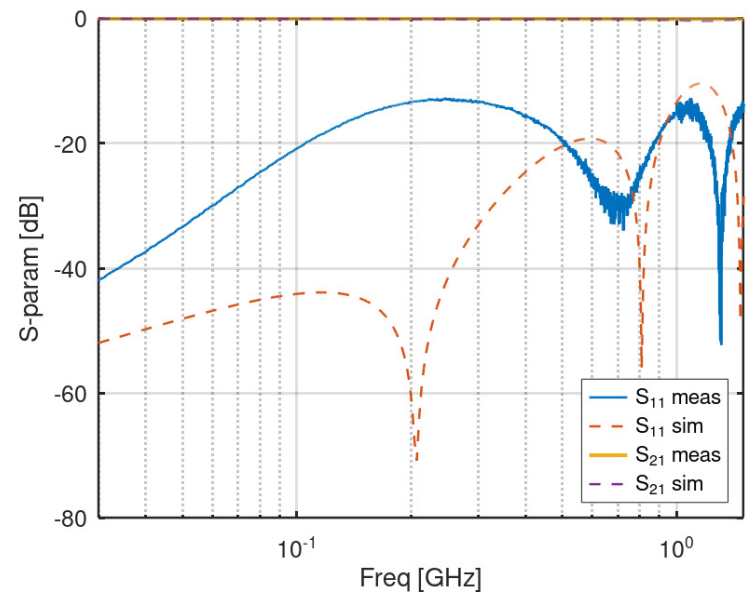

Fig. 5. Comparison of measured S-parameters (solid line) and simulated ones (dashed line) of the flange.
Responses differ at lower frequencies mainly (up to $\sim 0.5 \mathrm{GHz}$ for $S_{11}$ ) due to the material simplification in the simulation model. And moreover, connectors on the flange were not taken into the account in simulations.

In simulations, production inaccuracies and tolerances were not considered. Since the coaxial flange is assembled from two halves, an imperfect combination of these halves can result in a capacity bond which can mainly influence measurements at lower frequencies.

When comparing measurements and simulations, the dynamic measurement range has to be taken into account as well. Here, the $S_{21}$ parameter reaches the value about $-90 \mathrm{~dB}$ in measurements and the value about $-200 \mathrm{~dB}$ in simulations; such a small value of the simulated transmission coefficient can be hardly measured. The uncertainties described in Sec. 3 have to be added to measurements as well.

In order to reach a better agreement between measurements and simulations, models of a connector and wiring have to be developed and incorporated into the simulation model. Further, a tolerance analysis needs to be performed to evaluate the influence of manufacturing inaccuracies. The tolerance analysis shows that the critical role is played by the length of central pins and the dimensions determining the overall length of the coaxial flange.

Since the simulations were aimed to verify the fundamental functionality of the designed coaxial probe, additional analyses were performed in a limited extent.

Values $\left|S_{11}\right|<-15 \mathrm{~dB}$ and $\left|S_{22}\right|<-15 \mathrm{~dB}$ in the whole range of interest refer to good impedance matching on the both flange ports. Values $\left|S_{21}\right|>-1 \mathrm{~dB}$ and $\left|S_{12}\right|>-1 \mathrm{~dB}$ in the measuring range approve an accurate design of the whole flange.

The presented measurement method is based on a transversally split coaxial holder (Fig. 3). Into the holder, samples of a tested material are inserted. The measurement is based on comparison of capacitive coupling between the conductors in the holder when a load sample and a reference sample are inserted.

The method is applicable for frequencies from $30 \mathrm{MHz}$ to $1.5 \mathrm{GHz}$. For frequencies lower than $30 \mathrm{MHz}$, the measurement is not accurate due to imperfect capacitive coupling. High frequencies are limited by the excitation by higher wave modes.

The shielding efficiency is calculated by comparing attenuation of the reference sample and the load one.

\section{Measurement Uncertainty}

Operator-caused errors, sample-caused errors, and measurement system errors are considered to be the most significant errors.

Operator-caused errors may be caused by the lack of experience or training. No limits can be related to such 
errors. Nevertheless, the deviations might be large enough to indicate invalidity of results.

Sample-caused errors may appear due to irregularities in samples. Isotropic and homogeneous samples with smooth surfaces provide the most repeatable results. If the reference sample and the load one have different thickness, a bias error can appear. If thickness of both samples is the same but irregular, random errors might appear. Inhomogeneity or anisotropy of samples causes various effects depending on the size and the geometry. Measurement experience shows that acceptable measurement repeatability may be expected with exception of rough surfaces.

Measurement system errors are caused by impedance mismatch, generator instabilities, leakage paths, limited dynamic ranges, limited frequency ranges, receiver errors etc. Nevertheless, a well-trained operator can perform measurements over the appropriate frequency range and within the dynamic range of the system, can avoid leakage paths, can use suitable attenuators to avoid mismatch, can monitor and adjust input power to keep it constant. Then, measurement system errors may be reduced to a very modest part of the total error.

In Tab. 1, a summary of estimated errors is given for favorable conditions and a skilled operator. The systemic error in the receiver is irrelevant since shielding efficiency measurement is differential. The random error related to the drift over a few-minute time period is relevant.

If no attenuators are used, the mismatch error on the generator side is significant:

- With the reference sample in the holder, the impedance seen by the signal generator is determined almost entirely by the receiver.

- With the load sample in the holder, the impedance seen by the signal generator is almost a short circuit for conductive samples.

The impedance variation is reduced by the attenuator between the signal generator and the sample holder. The variation of the impedance level seen by the signal generator may also load the signal generator and cause the variation of the output power.

These variations can be monitored by a bidirectional coupler, and can be compensated. The couplers are not shown as a part of the setup in Fig. 1. So, the error due to the generator instability is not compensated. The magnitude of the corrections measured with a coupler determined the magnitude of the effect if no compensation is used.

\begin{tabular}{|l|c|c|}
\hline \multicolumn{1}{|c|}{ Source } & Systemic & Random \\
\hline Mismatch & $\pm 0.5 \mathrm{~dB}$ & $\pm 0.5 \mathrm{~dB}$ \\
\hline Power instability in signal generator & $\pm 0.4 \mathrm{~dB}$ & $\pm 0.4 \mathrm{~dB}$ \\
\hline Receiver calibration & $\pm 0.3 \mathrm{~dB}$ & $\pm 0.1 \mathrm{~dB}$ \\
\hline Total & $\pm 1.2 \mathrm{~dB}$ & $\pm 1.0 \mathrm{~dB}$ \\
\hline
\end{tabular}

Tab. 1. Summary of estimated uncertainties [12].

\section{Samples to Determine Optimal Structure}

In this section, samples measured by the presented method are described. The samples belong to carbon composites used in the aviation industry as a skin of aircraft. An overview of samples is given in Tab. 2, their photographs are shown in Fig. 7.

Measured samples are divided into two groups:

- Samples 1 to 6 are made from Carbon-Fiber-Reinforced Polymer (CFRP). For multiple layers, the layers are laid so that the fibers of the composite intersect by $45^{\circ}$ in each layer.

- Samples 8 to 13 consists of CFRP composite supplemented with a copper protective grid $(\mathrm{Cu})$. A layer of Glass-Reinforced Plastic (GRP) covers the front side to protect the $\mathrm{Cu}$ grid against mechanical damage and to smoothen the surface.

In addition, the $\mathrm{Cu}$ grid, which is protected by a GRP composite on both sides, is added as a sample 7 . The role of the $\mathrm{Cu}$ grid is played by a structure produced by DEXMET [28]. Structure of the grid is depicted in Fig. 6, including basic dimensions. The DEXMET grid is an expanded copper foil which is commonly used as an additional protection against lightning strikes.

\begin{tabular}{|r|l|r|r|r|}
\hline \multicolumn{1}{|c|}{$\#$} & Composition & Layers & $\begin{array}{c}\text { Weight } \\
{[\mathrm{g}]}\end{array}$ & $\begin{array}{c}\text { Thickness } \\
{[\mathrm{mm}]}\end{array}$ \\
\hline 1 & $1 \times \mathrm{CFRP}$ & 1 & 57.0 & 0.31 \\
\hline 2 & $2 \times \mathrm{CFRP}$ & 2 & 101.0 & 0.55 \\
\hline 3 & $3 \times \mathrm{CFRP}$ & 3 & 143.0 & 0.72 \\
\hline 4 & $4 \times \mathrm{CFRP}$ & 4 & 179.5 & 0.90 \\
\hline 5 & $6 \times \mathrm{CFRP}$ & 6 & 262.0 & 1.28 \\
\hline 6 & $8 \times \mathrm{CFRP}$ & 3 & 344.5 & 1.71 \\
\hline 7 & $2 \times \mathrm{GRP}+1 \times \mathrm{Cu}$ & 158.0 & 0.69 \\
\hline 8 & $1 \times \mathrm{GRP}+1 \times \mathrm{Cu}+1 \times \mathrm{CFRP}$ & 3 & 141.5 & 0.67 \\
\hline 9 & $1 \times \mathrm{GRP}+1 \times \mathrm{Cu}+2 \times \mathrm{CFRP}$ & 4 & 191.0 & 0.82 \\
\hline 10 & $1 \times \mathrm{GRP}+1 \times \mathrm{Cu}+3 \times \mathrm{CFRP}$ & 5 & 233.0 & 1.05 \\
\hline 11 & $1 \times \mathrm{GRP}+1 \times \mathrm{Cu}+4 \times \mathrm{CFRP}$ & 6 & 290.0 & 1.30 \\
\hline 12 & $1 \times \mathrm{GRP}+1 \times \mathrm{Cu}+6 \times \mathrm{CFRP}$ & 8 & 369.0 & 1.65 \\
\hline 13 & $1 \times \mathrm{GRP}+1 \times \mathrm{Cu}+8 \times \mathrm{CFRP}$ & 10 & 467.0 & 2.10 \\
\hline
\end{tabular}

Tab. 2. Parameters of measured samples.

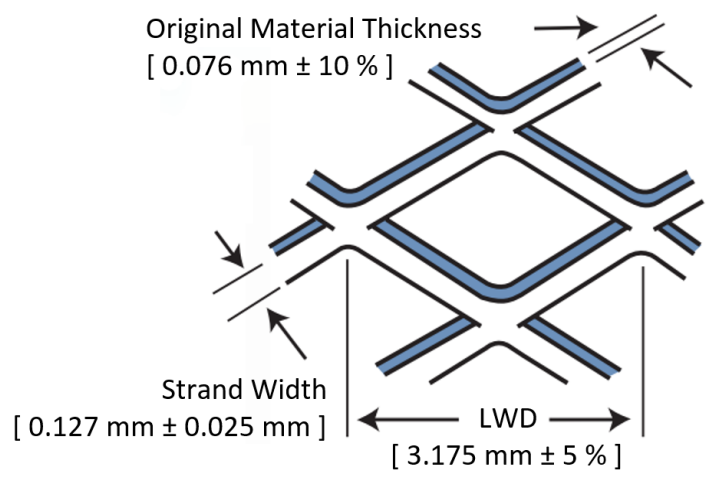

Fig. 6. Geometry and dimensions of the DEXMET grid 3CU7-125A [28]. 
a)

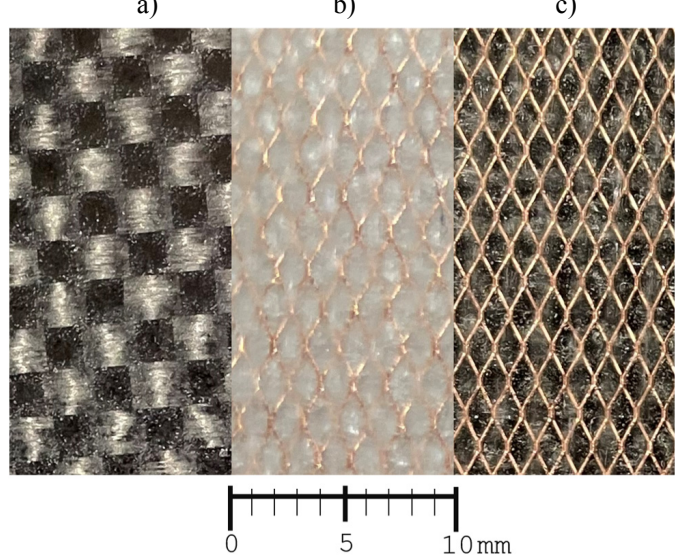

Fig. 7. Detailed photographs of the sample surfaces: a) samples 1-6, b) sample 7, c) samples 8-13.

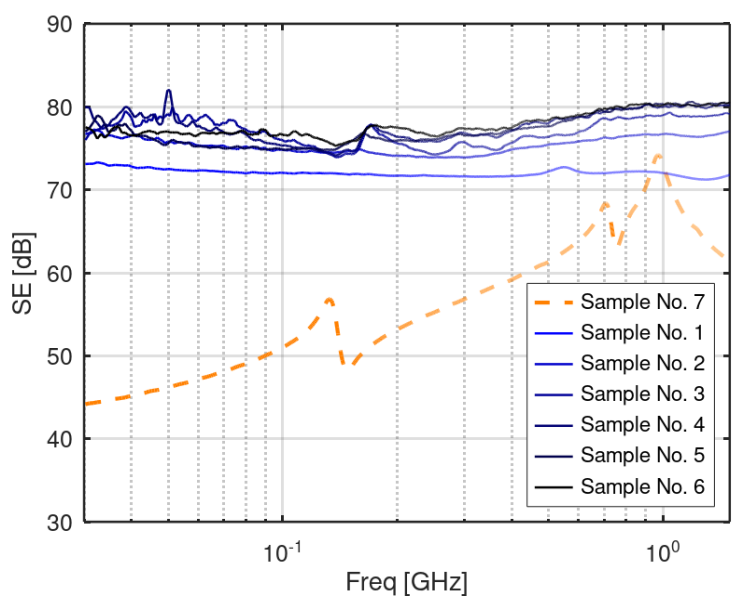

Fig. 8. Frequency response of shielding efficiency of CFRP composites (samples 1-6) and $\mathrm{Cu}$ grid + GRP (sample no. 7). Influence of the different number of layers.

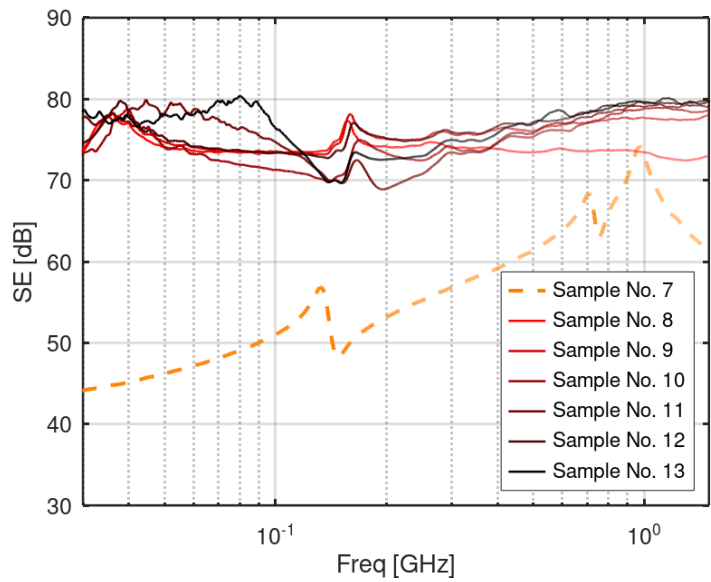

Fig. 9. Frequency response of shielding efficiency of CFRP protected composites (samples 8-13) and $\mathrm{Cu}$ grid + GRP (sample no. 7). Influence of the different number of layers.

All the samples were measured. Results were postprocessed and are displayed in Figs. 8 and 9.

Figure 8 shows frequency responses of shielding efficiency of CFRP composites without the protective $\mathrm{Cu}$ grid for the different number of layers (samples 1 to 6). Obviously, shielding efficiency grows with the increasing number of layers. There is practically no difference between 4 and 8 layers of CFRP (samples 4, 5 and 6).

Figure 9 shows a comparison of CFRP composites with the protective $\mathrm{Cu}$ grid (samples 8 to 13). Compared to the unprotected version, a slightly better shielding efficiency is reached but stronger resonances at lower frequencies can be observed. This behavior is probably caused by the combination of a carbon composite and a grid shape. Again, there is no significant difference of shielding efficiency between samples with 4, 6 or 8 layers (samples 11, 12 and 13$)$.

In Fig. 8 and 9, frequency response of shielding efficiency of the $\mathrm{Cu}$ grid (sample 7) is given as a reference.

Performed measurements show that the shielding efficiency of carbon composites is better than GRP composites protected by a $\mathrm{Cu}$ lattice (a higher number of GRP layers does not have a significant effect on shielding efficiency). This conclusion is valid for the protection against high intensity radiated fields (HIRF). When protecting the structure against lightning, a $\mathrm{Cu}$ lattice is necessary.

\section{Summary}

The paper deals with an original construction of a coaxial flange for the measurement of shielding efficiency of composite materials. The novel construction is aimed to improve properties of a standard coaxial flange D4935-10 [26].

In order to minimize the influence of a flange to obtained results, the measurement procedure was conceived as a differential method. Behavior of the coaxial flange was simulated in the transient solver of CST Microwave Studio to approve validity of measurements.

Using the developed measurement approach, the shielding efficiency of carbon fiber composites was studied. The studied materials exhibit a significant ability to shield electromagnetic radiation. For example, a carbon fiber structure with four layers and a thickness of $0.9 \mathrm{~mm}$ reaches shielding levels between $74.2 \mathrm{~dB}$ and $80.1 \mathrm{~dB}$.

The shielding efficiency of composites is rising with material thickness and with the number of fiber-to-fiber contacts. Thus, shielding efficiency is positively influenced not only by a higher volume fraction of fibers but also by continuity of conductive fibers along the transverse and parallel directions with respect to the incident wave.

The shielding efficiency increases with frequency.

In order to optimize the composite structure in terms of weight and shielding efficiency, only 4 layers of carbon composite are recommended to be used. More layers do not influence the shielding efficiency significantly. The results furthermore show financial and weight savings reached by replacing some layers with a glass fiber composite. 
Observing shielding efficiency of carbon composites protected by a $\mathrm{Cu}$ grid, no significant difference can be identified. The $\mathrm{Cu}$ grid only increases the shielding efficiency of glass-based composites. The $\mathrm{Cu}$ grid is used in combination with the carbon composite on the surface of aircraft as a protection against the lightning; currents up to $200 \mathrm{kA}$ can be conducted.

The presented measured data are going to be used for the calibration of equivalent homogeneous numerical models of composites. These models will be used to simulate the effects of lightning and HIRF on composite aircraft.

\section{Acknowledgments}

Research described in this paper received funding in frame of the specific research grant project FEKT-S-142281.

The research was also supported by the Clean Sky 2 Joint Undertaking (JU) under the grant agreement No. 945521. The JU receives support from the European Union's Horizon 2020 research and innovation program and the Clean Sky $2 \mathrm{JU}$ members other than the Union.

Special thanks belong to the EVEKTOR company for providing and manufacturing the coaxial flange.

\section{References}

[1] CUTLER, J. Understanding Aircraft Structures. $4^{\text {th }}$ edition. Oxford (UK): Blackwell Scientific Publications, 2006. ISBN: 9781-405-12032-6

[2] MILTON, G.W. The Theory of Composites. Cambridge University Press, 2002. ISBN: 9780511613357

[3] CAMPBELL, F. C. Structural Composite Materials. ASM International, 2010. ISBN: 978-1-61503-037-8

[4] BAKER, A., DUTTON, S., KELLY, D. Composite Materials for Aircraft Structures. $2^{\text {nd }}$ ed. AIAA Education Series, 2004. ISBN: 978-1563475405

[5] PETERS, S. T. (Ed.) Handbook of Composites. $2^{\text {nd }}$ ed. London (UK): Chapman \& Hall, 1998. ISBN: 978-0-412-54020-2

[6] CHRISTOPOUlOS, C. Principles and Techniques of Electromagnetic Compatibility. $2^{\text {nd }}$ ed. Boca Raton: CRC Press, 2007. ISBN: 9781315221960

[7] STEFFAN, P., VRBA, R., DRINOVSKY, J. A new measuring method suitable for measuring shielding efficiency of composite materials with carbon fibers. In The $5^{\text {th }}$ International Conference on Systems. Menuires (France), 2010, p. 186-189. DOI: 10.1109/ICONS.2010.39

[8] -, ASTM F3114-15, Standard Specification for Structures. [Online] Cited 2021-08-10. Available at: www.astm.org

[9] KESKIN, H. I., OZEN, S., ATES, K., et al. Analysis and measurement of the electromagnetic shielding efficiency of the multi-layered carbon fiber composite fabrics. In 2019 Photonics \& Electromagnetics Research Symposium - Spring (PIERS-Spring).
Rome (Italy), 2019, p. 4354-4360. DOI: 10.1109/PIERSSpring46901.2019.9017787

[10] LEE, J., JUNG, B., LEE, S., et al. FeCoNi coated glass fabric/polycarbonate composite sheets for electromagnetic absorption and shielding. In 2017 IEEE International Magnetics Conference (INTERMAG). Dublin (Ireland), 2017, p. 1-1. DOI: 10.1109/INTMAG.2017.8007811

[11] CHAKRADHARY, V. K., TAHALYANI, J., AKHTAR, M. J. Design of lightweight exfoliated graphite based thin composites for EMI shielding. In 2018 IEEE MTT-S International Microwave and RF Conference (IMaRC). Kolkata (India), 2018, p. 1-4. DOI: 10.1109/IMaRC.2018.8877128

[12] LEE, J., JUNG, B. M., LEE, S. B., et al. FeCoNi-coated glass fabric/polycarbonate composite sheets for slectromagnetic absorption and shielding. IEEE Transactions on Magnetics, 2017, vol. 53, no. 11, p. 1-4. DOI: 10.1109/TMAG.2017.2704663

[13] BARTH, D., CORTESE, G., LEIBFRIED, T. Evaluation of soft magnetic composites for inductive wireless power transfer. In 2019 IEEE PELS Workshop on Emerging Technologies: Wireless Power Transfer (WoW). London (UK), 2019, p. 7-10. DOI: 10.1109/WoW45936.2019.9030664

[14] JOO, K., LEE, K. J., HWANG, J. W., et al. High performance package-level EMI shielding of Ag epoxy composites with spray method for high frequency FCBGA package application. In 2018 IEEE 20th Electronics Packaging Technology Conference (EPTC). Singapore, 2018, p. 674-680. DOI: 10.1109/EPTC.2018.8654311

[15] SAVI, P., CIRIELLI, D., DI SUMMA, D., et al. Analysis of shielding effectiveness of cement composites filled with pyrolyzed biochar. In 2019 IEEE 5th International forum on Research and Technology for Society and Industry (RTSI). Florence (Italy), 2019 , p. 376-379. DOI: 10.1109/RTSI.2019.8895522

[16] SURAVARJHULA, V. K., MANAM, S. T., VENKATESAN, J., et al. Cement based composite loaded with medicinal package waste for low profile electromagnetic shielding. In 2018 USNCURSI Radio Science Meeting (Joint with AP-S Symposium). Boston (MA, USA), 2018, p. 29-30. DOI: 10.1109/USNCURSI.2018.8602658

[17] KÜHN, M., MESSER, M. Analysis of shielding enclosures based on CFRP materials. In 2019 Joint International Symposium on Electromagnetic Compatibility, Sapporo and Asia-Pacific International Symposium on Electromagnetic Compatibility (EMC Sapporo/APEMC). Sapporo (Japan), 2019, p. 420-423. DOI: 10.23919/EMCTokyo.2019.8893935

[18] VELICU, V., BUTNARIU, V., TRIP, B., et al. Experimental study of shielding composite materials for protection of computer systems. In 2021 12th International Symposium on Advanced Topics in Electrical Engineering (ATEE). Bucharest (Romania), 2021, p. 1-4. DOI: 10.1109/ATEE52255.2021.9425176

[19] RATHI, V., PANWAR, V., ANOOP, G., et al. Flexible, thin composite film to enhance the electromagnetic compatibility of biomedical electronic devices. IEEE Transactions on Electromagnetic Compatibility, 2019, vol. 61, no. 4, p. 1033-1041. DOI: 10.1109/TEMC.2018.2881267

[20] CATRYSSE, J., PISSOORT, D., VANHEE, F. Shielding effectiveness of planar materials: (semi)-standardized measurements from LF to $\mu \mathrm{W}$. In ESA Workshop on Aerospace EMC (Aerospace EMC). Valencia (Spain), 2016, p. 1-5. DOI: 10.1109/AeroEMC.2016.7504547

[21] GOMEZ DE FRANCISCO, P., POYATOS MARTINEZ, D., GALLARDO, B. P., et al. Limitations in the measurement of the shielding effectiveness of aeronautical multi-ply CFC laminates. In 2019 International Symposium on Electromagnetic Compatibility EMC EUROPE. Barcelona (Spain), 2019, p. 662-667. DOI: 10.1109/EMCEurope.2019.8872136 
[22] GALlARDO, B. P., GOMEZ DE FRANCISCO, P., ROMERO, S. F., et al. Limitations in the shielding effectiveness measurement methods for carbon fiber composites. IEEE Electromagnetic Compatibility Magazine, 2021, vol. 10, no. 1, p. 52-61. DOI: 10.1109/MEMC.2021.9400996

[23] DANIEL, I. M., ISHAI, O. Engineering Mechanics of Composite Materials. $2^{\text {nd }}$ ed. New York (USA): Oxford University Press, 2006. ISBN: 978-0195150971

[24] WILSON, P. F., MA, M. T. A Study of Techniques for Measuring the Electromagnetic Shielding Effectiveness of Materials. NBS Technical Note 1095. [Online] Cited 2021-08-10. Available at: www.govinfo.gov/content/pkg
[25] ČERNOHORSKÝ, D., NOVÁČEK, Z., RAIDA, Z. Electromagnetic Waves and Lines. Brno (Czech Republic): VUTIUM Publishing, 1999. (In Czech) ISBN: 80-214-1261-5

[26] -, ASTM D4935-10, Standard Test Method for Measuring the Electromagnetic Shielding Effectiveness of Planar Materials. [Online] Cited 2021-08-10. Available at: www.astm.org

[27] ADAMS, J. W., VANZURA, E. J. Shielding Effectiveness Measurements of Plastics. NBS Publications. [Online] Cited 202108-10. Available at: nvlpubs.nist.gov/nistpubs/Legacy/IR

[28] -, Dexmet Corporation, Manufacture Precision Expanded Metal Foils and Polymers. [Online] Cited 2021-08-10. Available at: www.dexmet.com 